DOI: 10.12731/2658-6649-2019-11-5-2-79-83

УДК 614.2

\title{
КОМПОНЕНТНЫЙ АНАЛИЗ СМЕРТНОСТИ НАСЕЛЕНИЯ КРАСНОЯРСКОГО КРАЯ
}

\author{
Миронова А.А., Параскевопуло К.М., Курбанисмаилов Р.Б., \\ Наркевич А.Н., Макушева Т.С.
}

В статье представлен вклад изменения смертности населения в различных возрастных группах, а также от различных причин в динамику ожидаемой продолжительности жизни (ОПЖ) населения Красноярского края за период с 1999 по 2017 г2. Установлено, что наибольший рост ОПЖ населения Красноярского края можно наблюдать за счёт снижения смертности от болезней системы кровообращения, а снижение ОПЖ - за счет изменения смертности от болезней нервной системы.

Ключевые слова: ожидаемая продолжительность жизни; компонентный анализ; смертность населения.

\section{COMPONENT ANALYSIS OF MORTALITY OF THE POPULATION OF THE KRASNOYARSK TERRITORY}

\section{Mironova A.A., Paraskevopoulo K.M., Kurbanismailov R.B., Narkevich A.N., Makusheva T.S.}

The article presents the contribution of changes in mortality in different age groups and from various causes in the dynamics of life expectancy (LE) of population of the Krasnoyarsk region for the period from 1999 to 2017 Established that the largest increases in LE the population of Krasnoyarsk region can be observed due to the reduction of mortality from diseases of the circulatory system, but reducing the $L E$ - due to changes in mortality from diseases of the nervous system.

Keywords: life expectancy; component analysis; mortality.

Ожидаемая продолжительность жизни (ОПЖ) - показатель, который отражает сколько в среднем будут жить люди, родившиеся в этом году, если 
смертность при этом будет неизменной [1], он независим от особенностей возрастной структуры и удобен для анализа в динамике [2]. Этот показатель крайне важен для оценки демографического состояния в стране.

Целью данной работы является: определение причин смерти, которые вносят наибольший вклад в изменение ожидаемой продолжительности жизни населения Красноярского края.

\section{Материалы и методы исследования}

Использованы базы данных зарегистрированных случаев смерти в Красноярском крае с 1999 по 2017 год и базы данных численности населения с 1999 по 2018 год. Для проведения компонентного анализа влияния изменения смертности в разных возрастных группах и по различным причинам смерти на динамику ОПЖ, была использована методика Е. E. Arriaga [3].

\section{Результаты исследования}

На начальном этапе исследования были определены повозрастные компоненты смертности населения Красноярского края в период с 1999 по 2017 год. Данные компоненты среди всего населения имели следующие значения: младенческий возраст (до 1 года) - 1,27, 1-4 года - 0,22, 5-9 лет $0,10,10-14$ лет - 0,02, 15-19 лет - 0,21, 20-24 года - 0,41, 25-29 лет - 0,36, 30-34 года - 0,29, 35-39 лет - 0,24, 40-44 года - 0,40, 45-49 лет - 0,62, 5054 года - 0,69, 55-59 лет - 0,60, 60-64 года - 0,55, 65-69 лет - 0,48, 70-74 года $-0,45,75-79$ лет $-0,27,80-84$ года $-0,19,85-89$ лет $-0,07$ и 90 лет и старше - 0,04. Среди мужчин данные компоненты имели следующие значения: младенческий возраст - 1,31, 1-4 года - 0,20, 5-9 лет - 0,09, 10-14 лет - 0,03, 15-19 лет - 0,25, 20-24 года - 0,57, 25-29 лет - 0,49, 30-34 года 0,40, 35-39 лет - 0,38, 40-44 года - 0,53, 45-49 лет - 0,79, 50-54 года - 0,81, $55-59$ лет - 0,64, 60-64 года - 0,52, 65-69 лет - 0,35, 70-74 года - 0,29, 75-79 лет $-0,13,80-84$ года $-0,07,85-89$ лет $-0,02$ и 90 лет и старше $-0,03 ;$ среди женщин: младенческий возраст - 1,20, 1-4 года - 0,23, 5-9 лет - 0,10, 10-14 лет - 0,01, 15-19 лет - 0,15, 20-24 года - 0,20, 25-29 лет - 0,16, 30-34 года $0,11,35-39$ лет - -0,01, 40-44 года - 0,17, 45-49 лет - 0,31, 50-54 года - 0,42, 55-59 лет - 0,42, 60-64 года - 0,46, 65-69 лет - 0,57, 70-74 года - 0,63, 7579 лет $-0,47,80-84$ года $-0,36,85-89$ лет $-0,13$ и 90 лет и старше $-0,06$.

На втором этапе исследования были определены компоненты изменения ОПЖ, связанные с изменением смертности от различных причин. Так, изменение ОПЖ связанное с динамикой смертности от инфекционных и паразитарных болезней (I класс) составило 0,10 года, новообразований 
(II класс) - 0,20 года, болезней крови, кроветворных органов и отдельных нарушений, вовлекающих иммунный механизм (III класс) - -0,01 года, болезней эндокринной системы, расстройств питания и нарушений обмена веществ (IV класс) - 0,01 года, психических расстройств и расстройств поведения (V класс) - 0,14 года, болезней нервной системы (VI класс) $-0,27$ года, болезней уха и сосцевидного отростка (VIII класc) - 0,01 года, болезней системы кровообращения (IX класс) - 3,90 года, болезней органов дыхания (X класс) - 0,84 года, болезней органов пищеварения (XI класс) $-0,04$ года, болезней кожи и подкожной клетчатки (XII класс) - -0,02 года, болезней костно-мышечной системы и соединительной такни (XIII класс) 0,01 года, болезней мочеполовой системы (XIV класс) - 0,01 года, осложнений беременности, родов и послеродового периода (XV класс) - 0,02 года, отдельных состояний, возникающих в перинатальном периоде (XVI класс) - 0,50 года, врожденных аномалий (пороков развития), деформаций и хромосомных нарушений (XVII класс) - 0,29 года, симптомов, признаков и отклонений от нормы, выявленных при клинических и лабораторных исследованиях, не классифицированных в других рубриках (XVIII класс) 0,97 года и внешних причин смерти (XX класс) - 0,82 года.

\section{Обсуждение}

В целом наблюдается положительный вклад изменения смертности на динамику ОПЖ во всех возрастных группах, кроме возрастной группы 35 39 лет у женщин. В большой степени снижает JG: среди всего населения смертность от болезней крови, кроветворных органов и отдельных нарушения, вовлекающие иммунный механизм (III); нервной системы (VI); органов пищеварения (XI); кожи и подкожной клетчатки (XII). Изменения смертности от остальных причин вносят положительный вклад в динамику ОПЖ. Наибольший положительный вклад в динамику ОПЖ можно наблюдать за счёт изменения смертности от болезней системы кровообращения (IX).

\section{Заключение}

Таким образом, проведён компонентный анализ смертности населения Красноярского края, результаты которого позволяют выделить причины смерти, в наибольшей степени влияющие как на рост ОПЖ населения Красноярского края, так и на его снижение. Анализируя полученные результаты удалось установить, что наибольший рост ОПЖ населения Красноярского края можно наблюдать за счёт снижения смертности от болезней системы кровообращения (IX), а снижение - за счет изменения смертности от болезней нервной системы (VI). 


\section{Сиисок литературы}

1. Леманова П.В. Социальная политика в управлении развитием человеческого капитала: уч. пос. М.: Изд-ий дом Академии Естествознания, 2016. 228 с.

2. Кулак А.Г. Теоретические основы статистической оценки факторов, вызывающих потери продолжительности жизни // Вестник кафедры статистики Российского экономического университета имени Г.В. Плеханова. 2018. С. 145-148.

3. Arriaga E.E. Measuring and explaining the change in life expectancies // Demography. 1984. Vol. 21, № 1, pp. 83-96.

\section{References}

1. Lemanova P.V. Sotsial'naya politika v upravlenii razvitiem chelovecheskogo kapitala: ucheb. posobie [Social policy in the development management of human capital: a training manual]. M.: Izdatel'skiy dom Akademii Estestvoznaniya, 2016. 228 p.

2. Kulak A.G. Teoreticheskie osnovy statisticheskoy otsenki faktorov, vyzyvayushchikh poteri prodolzhitel'nosti zhizni [Theoretical bases of statistical estimation of the factors causing life expectancy losses]. Vestnik kafedry statistiki Rossiyskogo ekonomicheskogo universiteta imeni G.V. Plekhanova. 2018, pp. 145-148.

3. Arriaga E.E. Measuring and explaining the change in life expectancies. Demography. 1984. Vol. 21, № 1, pp. 83-96.

\section{ДАННЫЕ ОБ АВТОРАХ}

Миронова Алена Андреевна, аспирант

Красноярский государственный медицинский университет имени профессора В.Ф. Войно-Ясенеикого

ул. Партизана Железняка, 1, г. Красноярск, 660022, Российская Федераиия 2800817@mail.ru

\section{Параскевопуло Константин Михайлович, студент}

Красноярский государственный медицинский университет имени профессора В.Ф. Войно-Ясенеикого

ул. Партизана Железняка, 1, г. Красноярск, 660022, Российская Федераиия darkslave9595@gmail.com

Курбанисмаилов Ренат Бадрудинович, аспирант

Красноярский государственный медицинский университет имени профессора В.Ф. Войно-Ясенецкого

ул. Партизана Железняка, 1, г. Красноярск, 660022, Российская Федераиия krasgmu05@mail.ru. 
Наркевич Артем Николаевич, доцент

Красноярский государственный медииинский университет имени профессора В.Ф. Войно-Ясенеикого

ул. Партизана Железняка, 1, г. Красноярск, 660022, Российская Федерачия

narkevichart@gmail.com.

Макушева Татьяна Сергеевна, студент

Красноярский государственный медицинский университет имени профессора В.Ф. Войно-Ясенеикого

ул. Партизана Железняка, 1, г. Красноярск, 660022, Российская Федераиия tanua.makusheva@yandex.ru

DATA ABOUT THE AUTHORS

Mironova Alena Andreevna, postgraduate Krasnoyarsk state medical university

1, Partizana Zheleznyaka Str., Krasnoyarsk, 660022, Russian Federation 2800817@mail.ru

Paraskevopulo Konstantin Mikhailovich, student

Krasnoyarsk state medical university

1, Partizana Zheleznyaka Str., Krasnoyarsk, 660022, Russian Federation darkslave9595@gmail.com

Kurbanismailov Renat Badrudinovich, postgraduate

Krasnoyarsk state medical university

1, Partizana Zheleznyaka Str., Krasnoyarsk, 660022, Russian Federation krasgmu05@mail.ru

Narkevich Artem Nikolaevich, associate professor

Krasnoyarsk state medical university

1, Partizana Zheleznyaka Str., Krasnoyarsk, 660022, Russian Federation narkevichart@gmail.com

Makusheva Tatyana Sergeevna, student

Krasnoyarsk state medical university

1, Partizana Zheleznyaka Str., Krasnoyarsk, 660022, Russian Federation tanua.makusheva@yandex.ru 